\title{
Subcutaneous Heterotopic Ossification Suspected as Skin Cancer
}

\author{
Sae Hwi Ki ${ }^{1,2}$, Seung Hyun $\mathrm{Sim}^{1}$, Sung Hwan $\mathrm{Ma}^{1}$ \\ ${ }^{1}$ Department of Plastic Surgery, Inha University Hospital, Incheon; ${ }^{2}$ Department of Plastic Surgery, Inha University School of Medicine, Incheon, Korea
}

\begin{abstract}
Skin ulcerations on old scars such as post-burn scar contractures are often suspected to be skin cancer. A 68-year-old woman with a 2-year-old skin ulceration, $1 \mathrm{~cm}$ in diameter, on her right anterior thigh, was initially suspected to be have Marjolin's ulcer. The patient had burnt her legs and trunk 50 years ago and had undergone hip joint arthroplasty 10 years previously. We suspected Marjolin's ulcer and performed a biopsy for diagnosis in an outpatient clinic. However, the histopathology indicated chronic inflammation. As routine X-rays revealed linear calcifications of the subcutaneous layer of the anterior thigh, we removed the area of calcification, including the skin ulceration. The surgical wound healed without complication. While heterotopic ossification is usually found in muscle layers around large joints, or in muscle layers subjected to trauma or surgery, its cause is unclear. We report a rare case of skin ulceration caused by subcutaneous tissue heterotopic ossification, which was initially mistaken as skin cancer, and ultimately treated with surgical resection.
\end{abstract}

Keywords: Skin neoplasm; Ossification, heterotopic; Burn; Subcutaneous tissue

\section{Introduction}

Though physicians suspect Marjolin's ulcer in cases of chronic skin ulcerations, including those found in areas of post-burn scar contracture [1], a condition not to be mistaken as Marjolin's ulcer is heterotopic ossification (HO). $\mathrm{HO}$ is caused by the formation of extraskeletal bone from calcium abnormally deposited in soft tissues, but its underlying cause is not known. HO usually occurs in burn patients or after hip arthroplasty, fracture, dislocation, or general paralysis [2], and is usually found in muscle layers subjected to trauma or surgical sites and around joints [3]. This report is to discuss the cause, clinical character, and the treatment method used for a case of unusual skin ulceration initially suspected as skin cancer, which was actually caused by $\mathrm{HO}$ of subcutaneous tissue in the patient's thigh. The study was performed in accordance with the principles of the Declaration of Helsinki. The informed consent was waived.

\section{Case}

A 68-year-old woman who had burnt her right thigh 50 years previously and had undergone hip joint hemiarthroplasty 10 years ago visited our department with a 2-yearold skin ulceration, $1 \mathrm{~cm}$ in diameter, on her right anterior thigh (Fig. 1). We suspected Marjolin's ulcer and performed a biopsy and a routine X-ray. Histopathology showed fibrosis and calcification of the subcutaneous fat layer, accompanied by chronic inflammation but no evidence of skin cancer. The X-ray revealed multiple

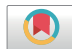

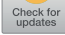 \\ Case Report \\ Received: June 1, 2019 \\ Revised: August 5, 2019 \\ Accepted: August 9, 2019

\section{Corresponding author:} \\ Sae Hwi Ki, M.D., Ph.D. \\ Department of Plastic Surgery, Inha University \\ School of Medicine, 27 Inhang-ro, Jung-gu, \\ Incheon 22332, Korea \\ Tel: +82-32-890-3619 \\ Fax: +82-32-890-2918 \\ E-mail: mdki67@naver.com
}

This is an Open Access article distributed under the terms of the Creative Commons Attribution Non-Commercial License (http://creativecommons.org/licenses/by-nc/4.0/) which permits unrestricted non-commercial use, distribution, and reproduction in any medium, provided the original work is properly cited.

C 2019 Korean Wound Management Society 
Ki SH et al.

Subcutaneous heterotopic ossification

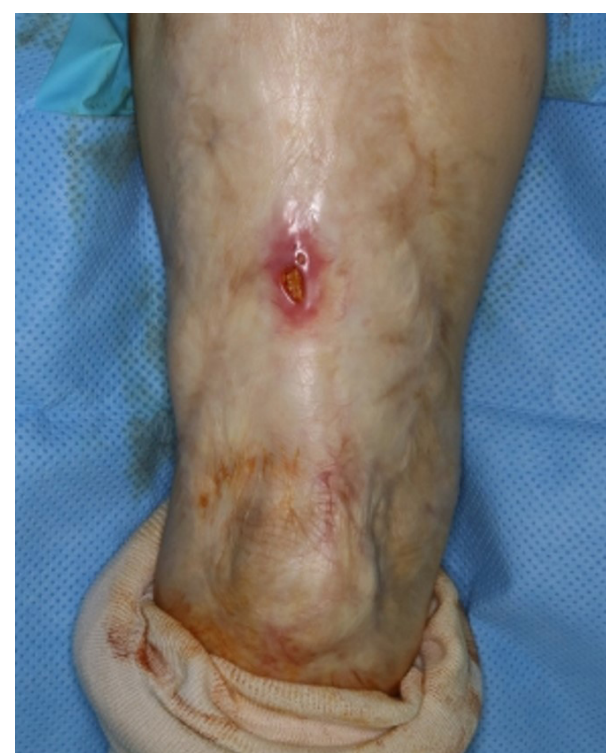

Fig. 1. Skin ulceration on the right thigh.

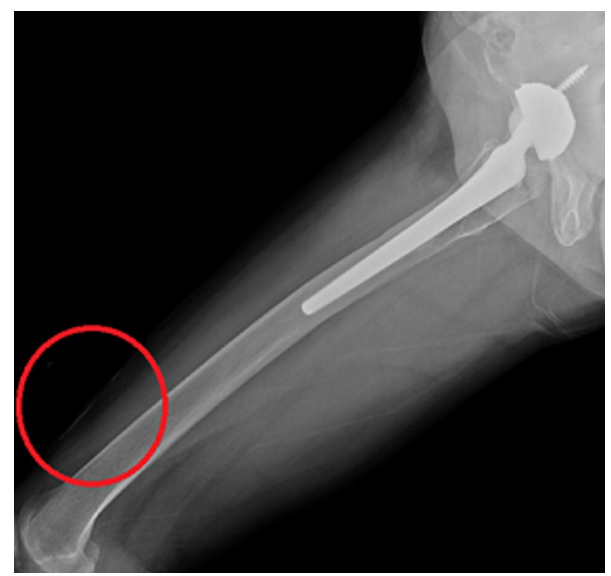

Fig. 2. Photograph of preoperative X-ray. Subcutaneous linear calcification in subcutaneous fat tissue (red circle).

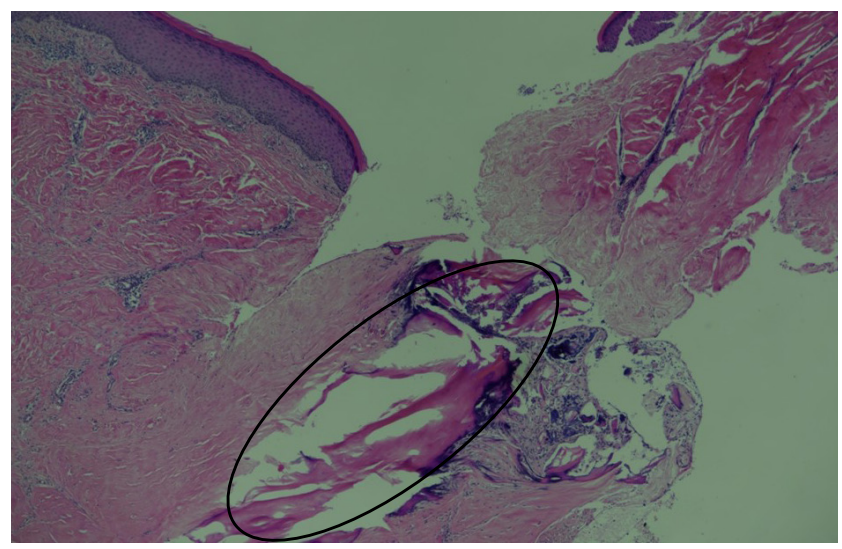

Fig. 3. Histopathology of the ulcer. Subcutaneous bone trabecula in elliptical circle (H\&E, $\times 40)$.
JWMR

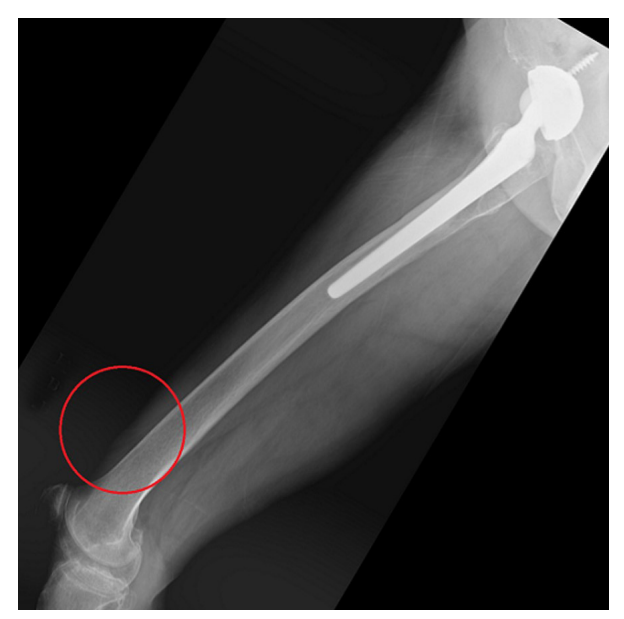

Fig. 4. Photograph of preoperative X-ray. No calcification visible in previous site (red circle).

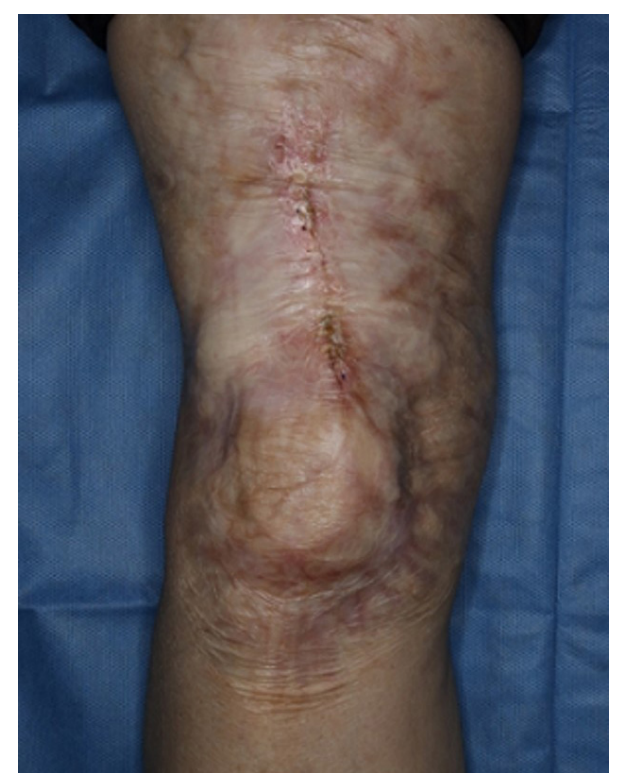

Fig. 5. Excised subcutaneous heterotopic ossification.

linear bony calcifications in subcutaneous tissues (Figs. 2, 3), but no calcifications in the hip joints or muscle. Serum calcium, phosphorus, and alkaline phosphatase levels were within normal ranges (calcium, $9.4 \mathrm{mg} / \mathrm{dL}$; phosphorus, $3.5 \mathrm{mg} / \mathrm{dL}$; alkaline phosphatase, $83 \mathrm{IU} / \mathrm{L}$ ). We diagnosed skin ulceration due to $\mathrm{HO}$ of subcutaneous tissue, and excised the skin ulceration along with the heterotopic calcification. The excised wound was closed with Prolene 4-0 and nylon 5-0. The wound healing process was uneventful (Figs. 4, 5). After the operation, she had no calcification or ulceration on her thigh for 11 months. 
$\mathrm{Ki} \mathrm{SH}$ et al.

Subcutaneous heterotopic ossification

\section{Discussion}

Marjolin's ulcer is an aggressive ulcerating form of squamous cell carcinoma that presents in areas previously traumatized or in chronically inflamed or scarred skin [1]. When Marjolin's ulcer is suspected, biopsy, computed tomography, and magnetic resonance imaging are usually performed for accurate diagnosis and to also to assess the extent of the tumor.

Meanwhile, HO mostly occurs after a severe burn or trauma [4]. HO associated with previous burn injury, fracture, dislocation, or limb paralysis takes place around joints and muscles, and is caused by abnormal bone morphogenic protein (BMP) expression in injured muscle. Conditions that precede the onset of $\mathrm{HO}$ include trauma, hematoma, signals arising from inflammatory reactions at sites of injury, and an environment conducive to $\mathrm{HO}$, such as immobilization and extended bed rest.

Furthermore, the incidence and severity of $\mathrm{HO}$ is related to the extent and location of a burn, how long movement had been limited, the degree and duration of paralysis, the time taken for wound healing, the presence of infection, hemorrhage, hypoxia, and the degree of post-traumatic hematoma $[5,6]$. Fibrodysplasia ossificans progressiva and traumatic myositis ossificans are also viewed as types of $\mathrm{HO}$.

Symptoms of HO, which is usually observed around large joints and muscle layers, include joint stiffness, joint dyskinesia, edema, pain, and dysfunction of the affected area. This type of ossification is found incidentally on radiographs. In the absence of symptoms, no special treatment is required, but when the joint is in pain, swelling, and motion is limited, it must be treated. Metabolic features of $\mathrm{HO}$ include normal calcium and phosphorus levels in serum. Elevated serum alkaline phosphatase levels observed at the initiation of bone formation are followed by a return to normal levels [7]. Prophylactic treatment including physical therapy can be performed if a patient is immobilized for an extended period of time due to neurologic causes, old age, or severe trauma, or when severe ossification is expected due to severe injury. Nonsteroidal antiinflammatory drugs and radiation therapy are suggested nonsurgical treatment methods. However, $\mathrm{HO}$ in the subcutaneous tissue layer is not associated with joint symptoms or stiffness. Instead, patients visit the hospital when there are symptoms such as a nonhealing ulcer, as in our case. When diagnosis and treatment are delayed for a protracted period the risk of malignant transformation is substantially increased [8], and when HO limits joint movement, surgical removal of ossifica- tions around joints is mandatory [3].

Several hypotheses have been proposed to explain the etiology of HO after trauma. Some physicians believe primitive mesenchymal cells may transform into osteogenic cells after trauma. Studies continue to show external stimuli result in the expression of osteogenic precursor cells and $\mathrm{HO}$, and that BMP plays an important role in this process. Several subtypes of osteogenic factors, that is, BMP 2, 4, 6, 7, and 9, regulate osteoblast regulation and bone formation [9]. Two types of cells are known to be involved in $\mathrm{HO}$ within the muscle, namely myogenic stem cells or satellite cells, and muscle-resident mesenchymal or stromal cells, which are present around connective tissues.

In cases of chronic skin ulceration, surgeons should suspect malignancies such as Marjolin's ulcer and squamous cell carcinoma. However, as skin ulcerations are not always skin cancer, it is imperative for clinicians to evaluate the routine X-ray and preoperative biopsy and remember to look for unusual skin lesion such as an unusual heterotopic calcification on postburn scar contractures.

\section{Conflict of interest}

No potential conflicts of interest relevant to this article are reported.

\section{Acknowledgments}

Sae Hwi Ki ～https://orcid.org/0000-0001-9194-9681

Seung Hyun Sim https://orcid.org/0000-0002-7513-1748

Sung Hwan Ma https://orcid.org/0000-0002-1956-9016

\section{References}

1. Phillips TJ, Salman SM, Bhawan J, et al. Burn scar carcinoma: diagnosis and management. Dermatol Surg 1998;24:561-5.

2. Kim JK, Cho SW, Kang SS. Heterotopic ossification combined with infection in the hand: a case report. J Korean Soc Surg Hand 2010;15:189-92.

3. Chen HC, Yang JY, Chuang SS, et al. Heterotopic ossification in burns: our experience and literature reviews. Burns 2009; 35:857-62.

4. Kaplan FS, Shen Q, Lounev V, et al. Skeletal metamorphosis in fibrodysplasia ossificans progressiva (FOP). J Bone Miner Metab 2008;26:521-30.

5. Levi B, Jayakumar P, Giladi A, et al. Risk factors for the devel- 
opment of heterotopic ossification in seriously burned adults: a national institute on disability, independent living and rehabilitation research burn model system database analysis. J Trauma Acute Care Surg 2015;79:870-6.

6. Orchard GR, Paratz JD, Blot S, et al. Risk factors in hospitalized patients with burn injuries for developing heterotopic ossification: a retrospective analysis. J Burn Care Res 2015;36: 465-70.

7. Engber WD, Reynen P. Post-burn heterotopic ossification at the elbow. Iowa Orthop J 1994;14:38-41.

8. Lee SY, Kim KS, Kim DY, et al. Dystrophic calcinosis cutis in a patient with squamous cell carcinoma secondary to postburn scar. Ann Plast Surg 2001;46:457-8.

9. Kang Q, Sun MH, Cheng H, et al. Characterization of the distinct orthotopic bone-forming activity of 14 BMPs using recombinant adenovirus-mediated gene delivery. Gene Ther 2004;11:1312-20. 